\title{
Sensitivity and Specificity in Urine Bladder Cancer Markers - Is it that Simple?
}

Florian Roghmann ${ }^{\mathrm{a}}$, Peter J. Goebell ${ }^{\mathrm{b}}$, Lars Dyrskjøt $\mathrm{t}^{\mathrm{c}, \mathrm{d}}$, Bas W.G. van Rhijn ${ }^{\mathrm{e}}$, Heiko U. Käfferlein ${ }^{\mathrm{f}}$, Oliver Hakenberg ${ }^{g}$, Arnulf Stenzl ${ }^{\mathrm{h}}$, Maximilian Burger ${ }^{\mathrm{i}}$, Beate Pesch ${ }^{\mathrm{j}}$, Natalya Benderska-Söder ${ }^{\mathrm{k}}$ and Bernd J. Schmitz-Dräger ${ }^{\mathrm{b}, \mathrm{k}, *}$

${ }^{a}$ Department of Urology, Marien Hospital, Ruhr-University Bochum, Herne, Germany

${ }^{\mathrm{b}}$ Department of Urology and Pediatric Urology, Friedrich-Alexander University, Erlangen, Germany

${ }^{\mathrm{c}}$ Department of Molecular Medicine, Aarhus University Hospital, Aarhus, Denmark

${ }^{\mathrm{d}}$ Department of Clinical Medicine, Aarhus University, Aarhus, Denmark

${ }^{\mathrm{e}}$ Department of Surgical Oncology, Division of Urology, The Netherlands Cancer Institute-Antoni van

Leeuwenhoek Hospital, Amsterdam, The Netherlands

${ }^{\mathrm{f}}$ Institute for Prevention and Occupational Medicine of the German Social Accidence Insurance, Institute of the Ruhr University Bochum (IPA), Bochum, Germany

${ }^{\mathrm{g}}$ Department of Urology, University of Rostock, Rostock, Germany

${ }^{\mathrm{h}}$ Department of Urology, Eberhard-Karls-University of Tübingen, Tübingen, Germany

${ }^{\mathrm{i}}$ Department of Urology, Caritas St. Josef Medical Center, University of Regensburg, Regensburg, Germany

${ }^{\mathrm{j}}$ Grefrath, Germany

${ }^{\mathrm{k}}$ Urologie 24, Nürnberg, Germany

Received 26 August 2021

Accepted 11 October 2021

Pre-press 27 October 2021

Published 11 March 2022

\begin{abstract}
Marker research, and in particular urine bladder cancer marker research throughout the past three decades, devours enormous scientific resources in terms of manpower (not to mention time spent on reviewing and editorial efforts) and financial resources, finally generating large numbers of manuscripts without affecting clinical decision making. This is mirrored by the fact that current guidelines do not recommend marker use due to missing level 1 evidence.

Although we recognize the problems and obstacles, the authors of this commentary feel that the time has come to abandon the current procedures and move on to prospective trial designs implementing marker results into clinical decision making. Our thoughts and concerns are summarized in this comment.
\end{abstract}

Keywords: Urinary tumor markers, bladder cancer, diagnosis, sensitivity, specificity

Urine biomarker sensitivity and specificity reports represent the backbone when evaluating the performance of urine tumor markers for diagnosis of

\footnotetext{
*Correspondence to: Bernd Schmitz-Dräger c/o Urologie 24, Mommsenstrasse 22 (Pavillon C), 90491 Nürnberg, Germany. Tel.: +49 9115699 10999; Fax: +49 9115699 10992; E-mail: bernd_sd@yahoo.de.
}

bladder cancer (BC). Nonetheless, decades of research in this field, frequently conducted in patients with established diagnoses of $\mathrm{BC}$, has not yet yielded a set of markers that either reliably supports or replaces cystoscopy in patients who exhibit symptoms indicative of BC. This is reflected by the fact that current guidelines do not recommend routine marker use due to missing level 1 evidence [1-3]. 
Thus, the usefulness of current research strategies must be questioned.

Even today, many clinical trials aimed at evaluating biomarker performance are case-control studies comparing patients with known disease to an often poorly defined healthy control group. The data retrieved from these study types will inevitably overestimate sensitivity if the same biomarker is evaluated in patients during routine follow-up for non-muscleinvasive bladder cancer (NMIBC) with mostly very small tumor recurrences. Recognizing that a significant number of the current study designs does not reflect a clinical scenario indicates that only prospective longitudinal assessment will provide reliable information.

So far, only one randomized controlled trial (RCT) is available that addresses the use of biomarkers in patient surveillance. This RCT questions the sensitivity of urethrocystoscopy (UCS) as the reference standard by using a urinary biomarker (microsatellite analysis (MA)) [4]. The authors observed that knowing the test outcome prior to UCS had a profound impact on the actual results $[4,5]$. In 131 UCS performed with knowledge of a positive test, 42 recurrences were detected, while only 6 recurrences were found at $120 \mathrm{UCS}$ without this information [5]. Hence, substantial under-estimation of sensitivity occurred if the urologist was not aware of the urinetest outcome. Specificity did not differ between both arms $(73 \%)$.

It must be considered that biomarkers may be positive in an anticipatory way even months before tumor recurrence becomes endoscopically visible [6]. This situation may be observed in up to $17 \%$ of cystoscopically "negative" patients. Despite the long search for less invasive methods for follow-up of BC patients, this phenomenon remains heavily understudied. Furthermore, molecular alterations typically associated with cancer driver mechanisms have been observed in the urothelium of healthy individuals using NGS methods [7], but the relevance to biomarker usage needs further investigation.

Due to a lack in available data, it remains unclear, how to respond to a positive marker result in a followup situation. While a thorough work-up of lower and upper urinary tract, potentially including random biopsies may be indicated in high-risk patients, this procedure might trigger over-diagnosis in patients with a low risk NMIBC. The fact, that longitudinal assessments demonstrate that a positive test may be followed by subsequent negative results further complicates decision making [8]. Furthermore, we need to study the role of field-effect alterations, which may cause positive biomarker tests in patients with negative cystoscopy [9].

For most biomarkers, sensitivity and specificity represent two pans on a scale: when one pan goes up, the other comes down. Consequently, the choice of biomarker and cut-off must consider the type of sensitivity that is clinically desired. It is obvious that high sensitivity is of utmost importance in surveillance of high risk NMIBC, while specificity in this context appear less relevant. The role of urine markers in this scenario is thus to improve sensitivity of UCS [10]. This may be different in surveillance of low-risk tumors where it is questionable if detection of very small lesions is desirable. It is conceivable that new definitions of the required sensitivity in these patients may include freedom from symptoms and a surgically manageable tumor size along with the necessity not to overlook tumor progression as a mandatory safety measure [11].

With regard to specificity, there is a difference if a biomarker is investigated as part of a screen of young healthy controls, or in patients under surveillance for high risk NMIBC, who also frequently suffer from other urological diseases [10]. Therefore, information on sensitivity and specificity is only useful together with comprehensive information on the background of data, sample retrieval and clinical task/circumstances. Meta-analyses of heterogeneous patient cohorts frequently derived from studies of debatable quality may yield results which require critical consideration.

In summary, current use and understanding of the assessment of sensitivity and specificity for urine biomarkers generates results that are difficult to apply to clinical questions, and continuation of current research practice is unlikely to yield results affecting clinical decision making. Thus, the authors feel that after decades of stagnation time has come to change to prospective trials and implement urine markers into clinical decision-making. Efforts, such as BLU-P and UroScreen or RCTs, e.g. CeFUB [4, 5], UroFollow [11], and SEALS Xpert, represent important steps in this direction and should pave the way to high quality marker research, shed new light on sensitivity and specificity and yield valid figures to permit subsequent translation into clinical decision making in the future.

\section{ACKNOWLEDGMENTS}

The authors have no acknowledgments. 


\section{FUNDING}

The authors report no funding.

\section{AUTHOR CONTRIBUTIONS}

\begin{tabular}{|c|c|c|}
\hline No. & Authors name & contribution \\
\hline 1 & Florian Roghmann & $\begin{array}{l}\text { conception; interpretation of } \\
\text { data; writing the article }\end{array}$ \\
\hline 2 & Peter J. Goebell & $\begin{array}{l}\text { interpretation of data; writing } \\
\text { the article }\end{array}$ \\
\hline 3 & Lars Dyrskjøt & $\begin{array}{l}\text { conception; interpretation of } \\
\text { data; writing the article }\end{array}$ \\
\hline 4 & Bas W.G. van Rhijn & $\begin{array}{l}\text { conception; interpretation of } \\
\text { data; writing the article }\end{array}$ \\
\hline 5 & Heiko U. Käfferlein & $\begin{array}{l}\text { interpretation of data; writing } \\
\text { the article }\end{array}$ \\
\hline 6 & Oliver Hakenberg & $\begin{array}{l}\text { interpretation of data; writing } \\
\text { the article }\end{array}$ \\
\hline 7 & Arnulf Stenzl & $\begin{array}{l}\text { interpretation of data; writing } \\
\text { the article }\end{array}$ \\
\hline 8 & Maximilian Burger & $\begin{array}{l}\text { interpretation of data; writing } \\
\text { the article }\end{array}$ \\
\hline 9 & Beate Pesch & $\begin{array}{l}\text { conception; interpretation of } \\
\text { data; writing the article }\end{array}$ \\
\hline 10 & Natalya & interpretation of data; writing \\
\hline 11 & $\begin{array}{l}\text { Benderska-Söder } \\
\text { Bernd J. } \\
\text { Schmitz-Dräger }\end{array}$ & $\begin{array}{l}\text { the article } \\
\text { conception; interpretation of } \\
\text { data; writing the article }\end{array}$ \\
\hline
\end{tabular}

All authors had full access to the manuscript, all authors support the content.

\section{CONFLICT OF INTEREST}

PJG, LD, BWGvR, AS and BJSD are Editorial Board members of this journal, but were not involved in the peer-review process nor had access to any information regarding its peer-review. FR, PJG, and $\mathrm{OH}$ are trialist for Cepheid Europe, France, Concile, Freiburg, Germany, Nextage Therapeutics Ltd, Tel Aviv, Israel, Arquer Ltd, Newcastle, UK and Nucleix Inc., Rehovot, Israel.

AS is consultant to Alere Inc., Waltham, MA, USA and Medical Enterprises EUROPE B.V., Amstelveen, The Netherands and acts as trialist for Cepheid Europe, France, Concile, Freiburg, Germany, Nextage Therapeutics Ltd, Tel Aviv, Israel, Arquer Ltd, Newcastle, UK, GenomeDx Biosciences Corp., San Diego, CA, USA and Nucleix Inc., Rehovot, Israel

BWGvR is scientific advisor for QED Therapeutics - a BridgeBio company, San Francisco, CA, USA.

BJSD has sponsored research agreements with and is consultant, speaker and trialist for Cepheid Europe, speaker and trialist for Concile, Freiburg,
Germany, and trialist for Nextage Therapeutics Ltd, Tel Aviv, Israel, Arquer Ltd, Newcastle, UK, and Nucleix, Rehovot, Israel.

LD has sponsored research agreements with $\mathrm{C} 2 \mathrm{i}$, AstraZeneca, Photocure, Natera and Ferring. LD has an advisory/consulting role at Ferring, and is Chairman of the Board in BioXpedia A/S.

HK, MB, BP and NB have no disclosures.

No disclosure of stock ownership.

\section{REFERENCES}

[1] Babjuk M, Burger M, Compérat E, Gontero P, Mostafid AH, Palou J, van Rhijn BWG, Rouprêt M, Shariat S, Sylvester $\mathrm{R}$, Zigeuner R. Guidelines on non-muscle invasive bladder cancer Ta, T1 and CIS. European Association of Urology 2018. http://www.uroweb.org/gls/. Accessed 07082019

[2] Leitlinienprogramm Onkologie (Deutsche Krebsgesellschaft, Deutsche Krebshilfe, AWMF): S3-Leitlinie Frü herkennung, Diagnose, Therapie und Nachsorge des Harnblasenkarzinoms, Langversion 1.1, 2016, AWMF-Registrierungsnummer 032/0380. online available: https://www. awmf.org/. last accessed: Aug 7th 2019.

[3] Hall MC, Chang SS, Dalbagni GT, Pruthi RS, Schellhammer PF, Seigne JD, Skinner EC, Wolf Jr. JS. Guideline for the Management of Nonmuscle Invasive Bladder Cancer: Stages Ta, T1 and Tis: Update (2014), online available: https://www.auanet.org/education/guidelines/bladdercancer.cfm; last accessed: Aug 7th, 2019.

[4] van der Aa MN, Zwarthoff EC, Steyerberg EW, Boogaard MW, Nijsen Y, van der Keur KA, van Exsel AJ, Kirkels WJ, Bangma C, van der Kwast TH. Microsatellite analysis of voided-urine samples for surveillance of low-grade non-muscle-invasive urothelial carcinoma: feasibility and clinical utility in a prospective multicenter study (CostEffectiveness of Follow-Up of Urinary Bladder Cancer trial [CEFUB]). Eur Urol. 2009;55(3):659-67.

[5] van der Aa MN, Steyerberg EW, Bangma C, van Rhijn BW, Zwarthoff EC, van der Kwast TH. Cystoscopy revisited as the gold standard for detection of bladder cancer recurrences: diagnostic review bias in a randomised prospective trial (Cefub-Trial). J Urol. 2010;183:76-80.

[6] Yoder BJ, Skacel M, Hedgepeth R, Babineau D, Ulchaker JC, Liou LS, Brainard JA, Biscotti CV, Jones JS, Tubbs RR. Reflex UroVysion testing of bladder cancer surveillance patients with equivocal or negative urine cytology: a prospective study with focus on the natural history of anticipatory positive findings. Am J Clin Pathol. 2007;127(2):295-301.

[7] Lawson ARJ, Abascal F, Coorens THH, Hooks Y, O’Neill L, Latimer C, Raine K, Sanders MA, Warren AY, Mahbubani KTA, Bareham B, Butler TM, Harvey LMR, Cagan A, Menzies A, Moore L, Colquhoun AJ, Turner W, Thomas B, Gnanapragasam V, Williams N, Rassl DM, Vöhringer H, Zumalave S, Nangalia J, Tubío JMC, Gerstung M, Saeb-Parsy K, Stratton MR, Campbell PJ, Mitchell TJ, Martincorena I. Extensive heterogeneity in somatic mutation and selection in the human bladder. Science. 2020;370(6512):75-82.

[8] Schmitz-Dräger C, Bonberg N, Pesch B, Todenhöfer T, Sahin S, Behrens T. Brüning T, Schmitz-Dräger BJ. Replacing cystosopy by urine markers in the follow-up of patients 
with low risk non muscle-invasive bladder cancer? - An IBCN project. Urol Oncol. 2016;34:452-9.

[9] Strandgaard T, Nordentoft I, Lamya P, Christensen E, Borg Houlberg Thomsen M, Jensen JB, Dyrskjøt L. Mutational analysis of field cancerization in bladder cancer. Bladder Cancer. 2020;6:253-264.

[10] Lotan Y, Black PC, Caba L, Chang SS, Cookson MS, Daneshmand S, Kamat AM, McKiernan JM, Pruthi RS, Ritch CR, Steinberg GD, Svatek RS, Zwarthoff EC. Optimal trial design for studying urinary markers in bladder cancer: a collaborative review. Eur Urol Oncol. 2018;1(3):223-230.
[11] Benderska-Söder N, Hovanec J, Pesch B, Goebell PJ, Roghmann F, Noldus J, Rabinovic J, Wichert K, Gleichenhagen J, Käfferlein HU, Köhler CU, Johnen G, Kernig K, Hakenberg O, Jahn D, Todenhöfer T, Stenzl A, Gleissner J, Gerwert K, El-Mashtoly S, Behrens T, Brüning T, Schmitz-Dräger BJ. Towards non-invasive follow-up of low risk bladder cancer - Rationale and concept of the UroFollow trial. Urol Oncol, 2020 Mar 18. pii: S1078-1439(20)30007-7 